\title{
HACIA EL BICENTENARIO:¿REPÚBLICA EN EXTINCIÓN?: UN DEBATE NECESARIO
}

\author{
TO THE BICENTENNIAL: REPUBLIC IN \\ EXTINCTION ?: A NECESSARY DEBATE
}

José Mendívil Nina

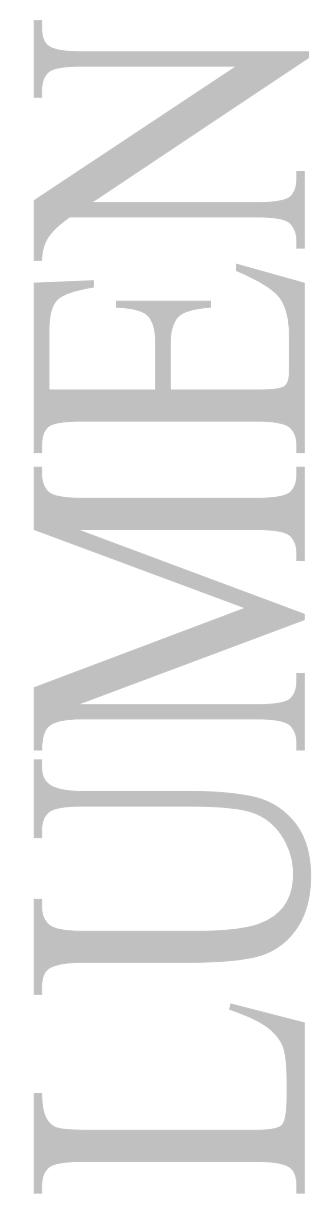




\title{
HACIA EL BICENTENARIO:¿REPÚBLICA EN EXTINCIÓN?: UN DEBATE NECESARIO
}

\author{
TO THE BICENTENNIAL: REPUBLIC IN EXTINCTION ?: A DEBATE \\ NECESSARY
}

José Mendívil Nina

Por eso, la promesa de la vida peruana atañe a la juventud.

Jorge Basadre

\begin{abstract}
RESUMEN
Sostengo que la extinción de nuestra república está ocurriendo, y que el problema que tendremos en el mundo que está llegando será el de la muerte definitiva de la promesa de la vida peruana de la que nos hablara Basadre; extinción que parece que nos ha sido destinada para su cumplimiento en el siglo XXII si seguimos siendo una república acostumbrada a perderse cotidianamente en los males de la corrupción y del autoritarismo, de la ilegalidad y el desgobierno, del atraso cultural y la marginalidad social, de la anomia y la rebeldía pasajera, de la ignorancia y la mediocridad, como si solo existiera para soportar derrotas y fracasos, burlas y escarnios, promesas fáciles y engaños repetidos, y hubiera sido fundada para la inevitable pérdida de las oportunidades que su devenir le ofrece.
\end{abstract}

\section{PALABRAS CLAVES}

Historia, república, extinción.

\begin{abstract}
ABSTRAT
I maintain that the extinction of our republic is taking place, and that the problem we will have in the world that is coming will be that of the definitive death of the promise of Peruvian life of which Basadre spoke to us; extinction that seems to have been destined for its fulfillment in the XXII century if we continue to be a republic accustomed to losing ourselves daily in the evils of corruption and authoritarianism, of illegality and misgovernment, of cultural backwardness and social marginality, of anomie and transient rebellion, ignorance and mediocrity, as if it only existed to withstand defeats and failures, ridicule and ridicule, easy promises and repeated deceptions, and would have been founded for the inevitable loss of opportunities that its future offers.
\end{abstract}

\section{KEY WORDS}

History, republic, extinction

\section{INTRODUCCIÓN}

A pocos años de la celebración del Bicentenario de la República peruana todavía es posible encontrarnos con historiadores que insisten en querer saber si la independencia del Perú fue conseguida o solo nos fue concedida. Entre ellos están Carlos Contreras y Miguel Glave, historiadores del Instituto de Estudios Peruanos que creen que su debate no ha perdido importancia, como puede leerse en La Independencia del Perú, libro en el que sostienen:

En nuestro caso, veremos cómo la que pareció nueva polémica, ya había tenido lugar un siglo atrás [...] Un cierto consenso otorga la construcción de una narrativa vinculada con una imaginada conciencia patriótica por lograr la emancipación de España a Mariano 
Felipe Paz Soldán en su Historia del Perú independiente [...] Allí se desdice a Vicuña Mackenna, a quien no cita, retrae la opinión general de la independencia a que se logró por los ejércitos y no trabaja los hechos previos a San Martín como lo hiciera el chileno. Fue rebatido por Francisco Javier Mariátegui, con sus recuerdos y documentos, en 1869, aunque Mariátegui, que valida así a Vicuña, no lo citara. Así, la polémica respecto a cómo interpretar el proceso de la independencia no se inauguró con los debates que acompañaron a la conmemoración del sesquicentenario, ni se terminaron allí, como ahora estamos viendo en el camino a la celebración del bicentenario (Carlos Contreras y Luis Glave, 2015).

Señalan que el debate sobre si la Independencia fue conseguida por una conciencia patriótica, o se logró por los ejércitos libertadores no fue iniciado por el provocador ensayo La independencia en el Perú: las palabras y los hechos que Bonilla y Spalding (1972) publicaran al año siguiente del Sesquicentenario, sino mucho antes por Mariano Felipe Paz Soldán y Francisco Javier Mariátegui, y que se dispone ahora de información documental que permite responder mejor a la pregunta de si la Independencia nos fue concedida o fue conseguida; asimismo afirman que si queremos conocer la verdad de este momento crucial de nuestra historia no deberíamos imaginar que la independencia fue necesariamente algo bueno (Carlos Contreras y Luis Glave, 2015, pág. 27), y que:

[...] ahora contamos con una cantidad estupenda de materiales para ponernos a pensar, nuevamente, un momento crucial en el devenir histórico de nuestro país: la independencia. No solo porque se vienen cumpliendo, aunque no conmemorando, los bicentenarios de los hitos principales del proceso emancipador, desde Tacna el 2011, Huánuco el 2012 y Cusco el 2014, y pronto nos avocaremos a la celebración del bicentenario de la proclamación limeña y sanmartiniana de la independencia el año 2021 venidero.

¿Sirven afirmaciones como estas para que pensemos nuestra historia de manera diferente y podamos imaginar los cambios que deberemos perseguir para ir en busca de la promesa de la vida peruana? Lo que Contreras y Glave dicen, admitámoslo, es de alguna forma la huella de un origen de nuestra República que parece ser aún inexplicable, origen que no ha dejado de perturbar y menoscabar los recuerdos que de nuestro pasado tenemos, y que, queramos o no, nos han dejado emociones que al parecer no podemos evitar y que nos dicen que algo fue mal hecho desde el inicio de la república, y que por mal habido ha terminado afectando inevitablemente a las formas en que percibimos nuestra peruanidad e imaginamos nuestro futuro, el que pareciera no tener otro destino que el de su inevitable fracaso; origen que por mal habido no ha dejado de afectar a nuestra sensibilidad para comprender y aceptar a nuestra historia tal como fue; sensibilidad que se ha hecho ajena bajo la influencia de la historiografía oficial que inventara una historia sin las huellas profundas del pasado del indio en nosotros, y que imaginó que estas serían borradas por el mestizaje que Pizarro y su hueste iniciaran con las acllas que el Inca Atahualpa tuviera para su divertimento y placer (Herren, 1997, pág. 215), y debilitado por la historiografía crítica, la que ha hecho de los acontecimientos más dolorosos de nuestro pasado heridas que no ha dejado de provocarnos malestar, historiografía que horada con insistencia en las derrotas y fracasos de nuestro pasado, y que no deja de decirnos que si todo sigue tan mal entre nosotros los peruanos es porque no hemos dejado de ser una república criolla y una nación en formación.

¿Independencia concedida o independencia conseguida? Es fácil advertir que las repuestas que se den a esta pregunta no aportarán nada importante a la comprensión de nuestra historia, sobre todo si se insiste en pensar la independencia desde esta falsa disyuntiva o problema. Si queremos pensar en forma distinta, podríamos empezar con la misma pregunta que Augusto Salazar Bondy hiciera en su ensayo Ideología de la emancipación (Bondy, 1973), escrito en las circunstancias del Sesquicentenario: ¿por qué se perdió la independencia? Podríamos también ampliar los retos del pensar diferente la independencia y la fundación de la República peruana preguntándonos: 
¿por qué los peruanos hemos desperdiciado las oportunidades que la historia nos ha dado y sigue ofreciéndonos para que podamos tener una República distinta a la que tenemos y en la que no hemos sabido resolver los problemas de su estabilidad política, gobernabilidad democrática y desarrollo científico y tecnológico?, o ¿por qué el futuro no llega a todo el territorio nacional?

Contreras y Glave deberían admitir que su pregunta no deja de tener la misma intencionalidad con la que Bonilla y Spalding ganaron notoriedad después del Sesquicentenario, y que si nacimos como una república criolla alejada del indio y la nación, como una república fracturada social y culturalmente, o como una república con un sustrato colonial que hizo imposible imaginar una comunidad nacional (Vich, 2003), se debió a la singularidad de la independencia que ni fue solo concedida ni solo conseguida como afirmaron Jorge Basadre, Alberto Flores Galindo y Pablo Macera a raíz del debate iniciado por Bonilla y Spalding (1972), República a la que le fue imposible entonces reconocerse en una misma condición humana o ciudadanía con el indio, y que poco después de la derrota de España en Ayacucho, con Bolívar en el gobierno, terminó con los privilegios que la élite incaica tuvo durante el virreinato (Amado, 2017); lo que significó el fin de la utilidad política que tuvieron durante casi tres siglos sus descendientes directos o no en el control social del indio para su explotación por la economía colonial y para evitar sus rebeliones.

La República recién fundada no pudo mejorar su economía y gobierno, lo que fue sin duda imposible desde una sociedad con costumbres coloniales y sin tradiciones de poder y autonomía basadas en la libertad y la igualdad; República carente de la vitalidad de un mismo pueblo y espíritu para imaginarse como una gran nación con un destino común, por lo que no pudo ni siquiera intentar seguir un rumbo parecido al que llevaría a Europa a la revolución industrial y a la modernidad, porque nada de su pasado podía comprometer a sus estamentos sociales en los cambios culturales y económicos que el fin del colonialismo español traía consigo, por lo que hasta mediados del siglo XIX prevalecieron en ella las disputas por el poder entre los caudillos militares vencedores en Ayacucho, período de nuestra historia que ha sido llamado el de la república en armas (Mc Evoy, C. y Rabinoich, A., 2018), o con continuas guerras civiles por el poder; República que solo pudo mostrar un proyecto republicano incierto y un escaso interés por lo nacional, los derechos y libertades ciudadanas que dijera perseguir desde la Constitución de 1823; ausencia de un destino común que solo fue posible imaginar recién a partir de 1879-1883, el que en alguna forma hizo posible la guerra del Pacífico al despertar el nacionalismo en todos los estamentos sociales, República que sin embargo no terminamos de comprender ni en su Centenario ni Sesquicentenario, y que desde fines de los años 60 del siglo pasado empezara a ver cambios en el significado de la comprensión de su historia a partir de la historiografía oficial de historiadores como José Agustín de la Puente Candamo o Gustavo Pons Muzo, y de la historiografía crítica de historiadores como Heraclio Bonilla o Alberto Flores Galindo, historiografías que aún se vienen enseñando en nuestros centros educativos y que forman las primeras imágenes y creencias que tenemos de lo que fue la independencia, es nuestra república y somos los peruanos, y ante las que poco ha podido hacer la historia escrita por historiadores como Jorge Basadre, Raúl Porras Barrenechea, Franklin Pease o Carmen Mc Evoy, y que han terminado afectando el interés que mostramos por nuestra historia (Pásara, 2017) y el destino de la peruanidad.

Desde la historiografía crítica se dice que somos una república sin ciudadanos (Galindo, 1994) o ciudadanos sin república (Vergara, 2018), es decir una república inacabada, una república en formación; en cambio para la historiografía oficial somos una república mestiza. Cualquier peruano sabe que no somos ni lo uno ni lo otro. Entonces ¿qué somos? Ambas historiografías evitan referirse a su influencia en la formación de nuestra predisposición social para convivir con el fracaso y el atraso, y para seguir sobreviviendo en una República que en sus casi 200 años de existencia política no ha sabido ser una República para todos los peruanos, ni encontrar una salida a los laberintos de sus desencuentros sociales y étnicos; al laberinto de las oportunidades perdidas por gobiernos sin ideas para el mañana de los peruanos y peruanas, lo que la ha llevado a su casi extinción al haberse alejado de la realización de la promesa de la vida peruana que nos legara Basadre (2004), 
quien combatiera con severidad tanto las inmoralidades de nuestra vida criolla, como los desbordes primitivos de nuestro radicalismo social, porque reducen, decía, la vitalidad de la peruanidad y las posibilidades de su engrandecimiento, y agregaba, que para que la promesa de la vida peruana fuera una realidad y no solo una esperanza, deberá ésta antes resolver el problema de un Estado que es parasitado por una burocracia abundante en vicios y que actúa separada de la ciudadanía, Estado al que llamó Estado yugo sobre el país:

Quitarle empirismo al Estado, decía Basadre, hacerle dar un rendimiento mayor, mucho mayor de utilidades sociales, estructurar la maquinaria administrativa y jurídica de modo que se libre de las taras burocráticas, de la lentitud en el expedienteo, de la incertidumbre o la miseria para sus servidores, del parasitismo en sus oficinas. Pero, al mismo tiempo, no hacer pesar al Estado como un yugo sobre el país y sobre el hombre peruano, conjugar una armoniosa convivencia entre esos tres factores: jel país estatal, el país nacional y el país humano! ¡Incrementar nuestra vitalidad como pueblo, lograr que eleve su nivel económico, intelectual, moral y social! ¡Recoger y proseguir, de acuerdo con el espíritu de cada momento histórico, lo que pudo haber de idealista, de progresista, de ímpetu de creación en quienes, en este suelo ungido por los siglos, dominaron a la naturaleza, fecundaron la tierra, fundaron hogares, crearon la Patria, dieron acento propio a nuestras cosas, simbolizaron, en suma, una actitud humanista, demócrata, liberal, social y creadora! ¡Ser conscientes de la inmensa tarea que falta por hacer; exigir para el planteamiento y la solución de cada caso, dos cualidades, justicia y eficacia; organizarse en línea de agresión contra todas las inmoralidades de nuestra vida criolla, desde los grandes o pequeños peculados, hasta los gritos radicales o reaccionarios, los desbordes primitivos y la mentira de nuestros convencionalismos! Querer un Perú en buena salud, no sólo por la acción, que debe ser fundamental y primordial sobre sus flagelos biológicos y sociales, sino también por la honestidad cívica. Eso es comprender y eso es querer cumplir en nuestros días la promesa de la vida peruana (Basadre, 2004).

Casi para nada ha servido lo que Basadre advirtiera, porque seguimos con un Estado separado de la ciudadanía, y con una burocracia abundante en inmoralidades y peculados, y nada indica que será reformado para mantener alguna esperanza en la promesa de la vida peruana, esperanza que quizá haya sido solo una ilusión a la que el mismo Basadre no pudo escapar, y no podremos escapar nosotros por habernos habituado a los desmanes de inmorales y prevaricadores que desde el poder no han dejado de desfigurar el presente de nuestra República, y permitido que la historiografía crítica y la historiografía oficial confundan y disminuyan la memoria de nuestra historia desde la escuela, y que se alienten los menoscabos del sentirnos peruanos de Perú(s) muy diferentes y distanciados, peruanos de un país de las mil caras, como le ha llamado Mario Vargas Llosa; un Perú que no podrá fácilmente dejar de mirarse con animadversión y desconfianza; historiografías que en lugar de liberar a nuestra vitalidad como pueblo, como reclamara Basadre, han preferido disminuirla en la repetición de nuestras frustraciones y traumas históricos que vienen del pasado, y que quizás acaben, si las dejamos, aletargando definitivamente el espíritu de la nación, espíritu que podría librarse de sus dudas sobre su devenir si la historia que se enseña sobre el Tahuantinsuyo, la conquista, el virreinato, la independencia y la fundación de la república dejara de ser una historia de procesos inacabados o ilusorios, es decir, una historia ajena o exagerada en sus logros y fracasos, y su memoria el lugar del retorno inevitable a los peores recuerdos, y en lugar de todo ello se reconstruyera la memoria de nuestro pasado como algo singular o excepcional, como algo que nos es propio y que permanece en su promesa desde su inicio; singularidad que nos viene de culturas y pueblos que nos han dejado lo que tenemos como patrimonio cultural y retos del futuro, y de las promesas de un republicanismo al que no le fue nada fácil organizar a la naciente república y regirse por los mecanismos de la democracia que anunciara su primera Constitución Política, y avanzar en la organización de la economía del país entre asonadas y golpes de Estado, derrotas y pérdidas territoriales particularmente hasta la guerra del pacífico; República que tardíamente, recién al final 
de los años 60 del siglo pasado, tuviera la oportunidad de iniciar el desarrollo de un capitalismo nacional y de vivir en democracia al liberarse al Estado y a la sociedad peruana del poder de las castas que hicieron de sus diferencias raciales su argamasa principal hasta pocos años antes de la celebración del Sesquicentenario; singularidad del proceso histórico de la Republica peruana que hace posible imaginar una formación distinta de la peruanidad, y que nos permitiría evitar el retorno enfermizo al lugar de la memoria traumática de la historiografía crítica, imaginar el sentido de lo que es singular en nuestro proceso histórico, el que deberá ser reinterpretado para ser contado en escuelas y universidades; ser parecido a lo que Gonzalo Portocarrero ha llamado historia justa (Portocarrero, 2007), para que sirva al renacimiento de una peruanidad hacedora al ser liberada de la ideología de lo inacabado y defectivo de la historia que le gusta contarnos a la historiografía crítica, y alejada de lo inerme y desprovisto de imaginación que viene de la historiografía oficial y el engaño de que somos una nación mestiza; y quizás de esta forma la memoria de nuestra historia cambie y sea el lugar de los mejores recuerdos, la narración de un proceso histórico diferente, de una historia que nos devuelva la confianza en que aún es posible ir hacia la promesa de la vida peruana, promesa que hemos descuidado por nuestra predisposición, como dijera Basadre, para el despedazamiento interno y el descuido de lo propio ante el espejismo de lo extranjero:

Fuimos, desde temprano, una promesa para el mundo, verdad es que no siempre hemos realizado esa promesa de la vida americana y que muchas de nuestras efemérides merecen el duelo y no el festejo. Pero precisamente eso se debe al que, a menudo, nos fascinó el despedazamiento interno o el espejismo de lo extranjero y no escuchamos la voz de nuestro propio e íntegro ser (Basadre, 2004, pág. 79).

Es muy difícil saber qué es o será nuestro propio e íntimo ser, que Basadre tomara de Heidegger para referirse al sentido de la peruanidad en la realización de su promesa, y a su proximidad que nos acerque a su goce, por lo que al referirse al Perú como una promesa para el mundo insistió en que esta no será posible mientras la República no salde cuentas con lo que en ella está podrido, como afirmara en Meditaciones sobre el Destino Histórico del Perú (1947), ensayo que compilara Ernesto Yepes en el libro Memoria y destino del Perú: Textos esenciales (Yepes, 2004), libro que reúne a los principales ensayos de Basadre sobre la República, y que haríamos bien en leer todos los peruanos y peruanas:

Por eso, la promesa de la vida peruana atañe a la juventud para que la reviva, a los hombres de estudio en sus distintos campos para que la conviertan en plan, a la opinión pública en su sector consciente para que la convierta en propósito. [...] Porque la promesa de la vida peruana sentida con tanta sinceridad, con tanta fe y con tanta abnegación por próceres y tribunos, ha sido a menudo estafada o pisoteada por la obra coincidente de tres grandes enemigos de ella: los Podridos, los Congelados y los Incendiados. Los Podridos han prostituido y prostituyen palabras, conceptos hechos e instituciones al servicio exclusivo de sus medros, de sus granjerías, de sus instintos y sus apasionamientos. Los Congelados se han encerrado dentro de ellos mismos, no miran sino a quienes son sus iguales y a quienes son sus dependientes, considerando que nadie más existe. Los Incendiados se han quemado sin iluminar, se agitan sin construir. Los Podridos han hecho y hacen todo lo posible para que este país sea una charca; los Congelados lo ven como un páramo; y los Incendiados quisieran prender explosivos y verter venenos para que surja una gigantesca fogata. Que el Perú no se pierda por la obra o la inacción de los peruanos (Basadre, 2004, págs. 77-78).

La verdad es que esta promesa ha sido descuidada por los prejuicios sociales que nos separan a los peruanos, y sin duda por los desvaríos ideológicos nacionalistas, liberales y socialistas aún en pugna en el Perú de este tiempo, y por una historiografía que ha servido a la formación de una memoria estropeada que ha dado lugar a dos proyectos historiográficos y políticos sobre nuestra 
historia y lo que debe ser la nación y la peruanidad; al proyecto de la nación mestiza sin el indio o con este reducido a una curiosidad antropológica de lo que fuera el Tahuantinsuyo; y al proyecto de la nación en formación, sin el criollo y con el indio reivindicado; proyectos que tienen todavía a sus epígonos y seguidores que van de José Carlos Mariátegui a Heraclio Bonilla, y en algún sentido de José de la Riva-Agüero a José Agustín de la Puente Candamo, y que son promovidos desde el Instituto Riva Agüero, y el Instituto de Estudios Peruanos, proyectos que no han servido ni a una memoria compartida, ni a la promesa de la vida peruana.

Y como el pasado sigue provocando más malestar que satisfacciones en nosotros los peruanos, la historiografía crítica actual se siente obligada a desempolvar lo que Bonilla y Spalding dijeron en su provocador ensayo La independencia en el Perú: las palabras y los hechos, ensayo que fue criticado por historiadores como Jorge Basadre y Alberto Flores Galindo, quien haciendo suya la propuesta de Pablo Macera de tener una visión alternativa de la independencia, refiriéndose a la apresurada afirmación de que la independencia nos fue concedida por los ejércitos libertadores de San Martín y Bolívar, dijo que la:

[...] independencia comienza en 1780 [...] Son evidentes los cambios que experimentó la sociedad peruana en los cincuenta años comprendidos entre 1780 y 1830 , pero también es cierto que fueron todavía mayores las expectativas que se abrieron para los sectores populares [...] no pensaban que una revolución podía limitarse a un cambio político o al desalojo de la aristocracia; la revolución para ellos, consciente o instintivamente, era el cambio sustancial de un ordenamiento, la inversión completa de la realidad (Carlos Contreras y Luis Glave, 2015).

Este giro en la explicación de nuestra historia moderna no cambiaría el sentido y las intenciones de la historiografía crítica que muestra un interés particular para que la nación en formación devenga en una república socialista que sustituya, dice, a la república criolla que fuera fundada en 1821 como resultado de lo que ha llamado la revolución frustrada de la independencia; república socialista que con acentuados matices andinos fuera anunciada inicialmente por Mariátegui y Valcárcel (Valcárcel, 1975), y que luego recogieran José Matos Mar y Manuel Burga, como si debiera ser la continuidad histórica de las rebeliones de indios e incas que se dieron entre los siglos XVIII, XIX y XX con la intención de restaurar el proyecto cultural del Tahuantinsuyo.

De esta forma la historiografía crítica, a la que se suman Contreras y Glave ha terminado creando una relación enfermiza entre las pretensiones de una idea crítica de nuestra historia, del pasado que nos interpela y perturba, y, lo que nuestra memoria quiere recordar como aquello que debe reposar finalmente entre los recuerdos de una historia que conserve lo mejor de su grandeza, como la memoria de una historia que tiene un porvenir por liberar, por hacerse y gozarse; relación por sí anómala y que no ha dejado de influir en la formación de nuestras emociones y en las formas en que percibimos nuestra historia, asumimos el sentido de la peruanidad y miramos el futuro del país, y que viene también de la historiografía oficial que terminó reduciendo las otras historias, las historias memoriales, como les ha llamado Lorenzo Huertas (2017), al lugar de lo marginal y anecdótico de nuestro pasado; relación desde la que la historiografía crítica no puede evitar mostrar su desencanto por una historia que se perdió entre tropelías y actos fallidos de indios y blancos. Pero, Contreras y Glave necesitan darle credibilidad y actualidad al debate que sugieren sobre la independencia, y para este fin afirman lo siguiente:

A diferencia de cuarenta años atrás, hoy parecemos más convencidos de que la ruptura con el gobierno español en 1821 fue un hito decisivo y crucial de nuestro proceso histórico. Décadas atrás, bajo la influencia de la historia económica y social, tendía a pensarse que tal ruptura fue un fenómeno básicamente superestructural, meramente político [...] Nos hemos convencido de que la evolución de la economía depende de la política, tanto 
como esta de aquella. La independencia ha recuperado, así, un sitial de hito divisor de nuestra historia, tanto como lo es la conquista española o la guerra del salitre (Carlos Contreras y Luis Glave, 2015).

Si bien se alejan del determinismo económico en el que Bonilla y Spalding incurrieran en su interpretación de la independencia a partir de la generalización de la idea de Marx sobre base y superestructura en el famoso Prólogo de Contribución a la crítica de la economía política (1856), y creen corregir cuando dicen que existe una relación de dependencia entre economía y política, es más útil advertir que no saben cómo librarse de sus prejuicios ideológicos sobre la independencia cuando después de destacar a ésta como un hito divisor de nuestra historia, dicen no estar tan convencidos de que fuera algo bueno:

La crisis de los Estados nacionales, y del nacionalismo que su modelo de organización política y social llevaba aparejado, ha producido, además, una cierta conciencia crítica entre los sectores más educados de la población acerca de la bondad de la independencia. Es decir, no estamos tan convencidos como ayer de que la independencia fuera necesariamente algo 'bueno'. Conquistarla tuvo un costo enorme en vidas humanas, expropiaciones y destrucción de riqueza de los particulares y envilecimiento de la economía pública y de nuestras instituciones, que aumentaron la dosis de corrupción, abuso del poder y desigualdad hasta niveles que superaron lo visto hasta entonces. Implicó, además, escindirnos de pueblos con quienes habíamos compartido un proceso común y de asociarnos podríamos habernos beneficiado en múltiples sentidos. Estamos más dispuestos a reconocer todo esto; medio siglo atrás hubiera pasado como un acto de traición a la patria (Carlos Contreras y Luis Glave, 2015)

Pareciera que no se detienen a pensar en lo que están afirmando cuando alegan que hace medio siglo habría sido un acto de traición a la patria reconocer que la República peruana tenía un destino común con los pueblos andinos que habían sido excluidos de la República desde su fundación, más aún si el contexto de lo que afirman es el de la reforma agraria de la propiedad de la tierra que terminó en 1969 con la servidumbre del indio en las haciendas; mostrando así que no pueden evitar arrastrar culpas por haber olvidado que tenemos un destino común con el indio, ni dejar de exteriorizar cierta frustración por lo que la independencia no pudo darnos. Esta forma de reconocer olvidos y reivindicar al indio es característica de la historiografía mestiza, de sus dudas y pesimismo sobre nuestra historia y el futuro de la nación peruana, por lo que Contreras y Glave (2015) necesitan agregar:

Decirlo no significa renegar de la independencia ni poner en duda la viabilidad del Perú como nación independiente. Implica sencillamente reconocer los enormes desafíos con que comenzó el país su vida su vida independiente, desafíos que poco a poco, hemos venido superando.

Sí afirmo que debemos dudar de la viabilidad del Perú como una nación independiente en este siglo, sí digo que nuestra República es una república en extinción y que el problema que tendremos en el mundo que está llegando será el de la muerte definitiva de la promesa de la vida peruana de la que nos hablara Basadre, lo que quiero decir es que sería irresponsable no advertir que este problema nos obliga a tratar de ver de otra manera los retos que vienen con el Bicentenario, porque la extinción que advierto pareciera haber sido destinada para su cumplimiento en el siglo XXII si seguimos siendo una República acostumbrada a perderse cotidianamente en los males de la corrupción y la mediocridad, y si los debates sobre nuestra historia no sirven para imaginar una nueva historia, que nos sirva para pensar en un Estado-nación diferente y para aproximarnos a la verdad de lo que somos, verdad que solo muestra su naturaleza, encantos y monstruosidades, como la que anuncio, solo a los que saben solazarse en su seducción y engaños para alcanzarla en su donación. 
Pero, ¿quéfue lo que dijeron Bonillay Spalding de la independencia después del Sesquicentenario?:

[...] si en Buenos Aires y en Caracas la aspiración a la independencia de la burguesía criolla nació del deseo de superar su inferioridad política y alcanzar en este campo la hegemonía plena para hacerla conciliable con su poderío económico, ello no ocurrió ni podía ocurrir en el Perú. Toda la fuerza económica de la clase hegemónica peruana, por el contrario, se nutrió de su vinculación con la metrópoli. Internamente no existieron ni las bases materiales ni los fundamentos ideológicos que impulsaran a la liberación. Tal vez, más bien, la esperanza de un reforzamiento de la situación colonial y lamentos por el esplendor perdido (Heraclio Bonilla y Karen Spalding, 1972, págs. 45-46).

Al afirmar que no existieron ni las bases materiales ni los fundamentos ideológicos que impulsaran a la liberación, no hacían sino repetir a Mariátegui que en 1828 dijo que no hubo una burguesía que fuera capaz de actuar como capitanes de la industria (Mariátegui, 2007, pág. 24) para que la independencia nos fuera más propia y auténtica.

Acentuando su exagerada interpretación de la independencia, dijeron también que:

La libertad económica no pudo ser exigida por una burguesía que creció y se benefició con la articulación colonial. El asalto al poder político tampoco pudo ser realizado por una burguesía profundamente débil, que vislumbraba con temor cualquier modificación de la situación colonial. Por esto, los atisbos de racionalismo y nacionalismo solo permanecieron al nivel de la formulación en hombres aislados, sin llegar a generalizarse. Aún más, este liberalismo se pronunció contra las revoluciones americanas que postularan la destrucción del imperio (Heraclio Bonilla y Karen Spalding, 1972, pág. 59).

Como he anotado, historiadores como Pablo Macera y Alberto Flores Galindo imaginaron entonces que más razonable era tener una visión alternativa de la independencia, continental le llamó Flores Galindo (1987), que explicara su complejidad y evitara el reduccionismo en que incurrieran Bonilla y Spalding, quienes propusieron que su interpretación estuviera referida al período que va de la revolución de Túpac Amaru en 1780, a la derrota de La Serna en Ayacucho en 1824, período que permitiera reconocer como precursoras a las rebeliones que antecedieron a la proclama de la independencia por San Martín.

Aparentemente este giro en el estudio de la independencia resolvía el debate provocado por la curiosa afirmación de la independencia concedida, pero Contreras y Glave (2015), desde el IEP, volverían a desempolvar esta idea convencidos de que su debate no había perdido actualidad para el bicentenario, por lo que como subtítulo del libro La independencia del Perú, dejan planteada la pregunta ¿concedida, conseguida, concebida?, y no se dan cuenta que esta no es la pregunta que debiéramos hacernos y responder cuando volvemos sobre la independencia, porque cualquiera que sea la respuesta que se dé, ella no aportará nada importante a la comprensión de nuestro pasado, ni a la comprensión de la historia de los que hicieron la independencia y fundaron la República para beneficiarse de ella, y mucho menos para tener una interpretación que nos acerque a los recuerdos de su entrega, de sus vidas, aventuras, fortunas perdidas y familias separadas; como a sus límites sociales y económicos, a sus carencias y miedos, para que podamos contarnos una historia que nos libre de la idea de que algo fue mal hecho desde la fundación de República, y de la creencia de que debemos terminar nosotros lo que los revolucionarios de 1821 y los constituyentes de 1822-1823 dejaron incompleto o a medio hacer; que nos aleje de las ilusiones de una historia posible y de lo que habría podido ser nuestra República de haber sido la revolución de la independencia muy diferente a lo que fue, y nos dé una historia escrita que nos libre de la mala historia que no ha hecho otra cosa que formar las estructuras subjetivas de nuestro repliegue sobre el pasado, y de una memoria que nos aleja de los que fundaron la República por la forma en que lo hicieron, sin que notemos que no solo se estaba cuestionando los límites que le impusieron desde sus creencias y circunstancias, 
sino que se reducían las posibilidades que tenemos de liberar a la peruanidad de lo más frustrante de su pasado, y que no hayamos reparado en que al empequeñecerse el cambio histórico que significó para las indias occidentales y el mundo europeo del siglo XIX las independencias y las repúblicas que se fundaron en esta parte del mundo, se estaba también estrechando las fronteras de la peruanidad en lo poco que pudo hacerse y cambiarse después de la independencia, formándose así una peruanidad predispuesta para reconocerse solo desde emociones y recuerdos encontrados sobre su pasado, que solo han servido para avivar resentimientos y prejuicios entre nosotros, y para que creamos que no nos queda sino evadirnos de esta realidad desde nuestras emociones más instintivas pretendiendo que todo siga igual, o que la revuelta y el tumulto refunden a la República para que todos nuestros males terminen.

Al referirse a los antecedentes de la idea de la 'independencia concedida', Alberto Flores Galindo señalaba:

Pero de manera quizá subterránea persistía una imagen opuesta que puede rastrearse en las desengañadas memorias de Pruvovena (seudónimo del primer presidente de la República) o en las reflexiones de un descendiente de este, el historiador José de la Riva-Agüero, haría en el campo de batalla de Ayacucho: ese paisaje le recuerda el destino errático del país que atribuye a la carencia de una 'clase directiva' dispuesta a infundir entusiasmos colectivos: '¡Pobre aristocracia colonial, pobre boba nobleza limeña, incapaz de toda idea y de todo esfuerzo!'. Estas intuiciones serían articuladas, años después, en los ensayos de José Carlos Mariátegui: recurriendo a la comparación con la unificación italiana, define a la independencia como una revolución frustrada; ahora podríamos decir como una 'revolución política', un cambio en las alturas, nada proclive a la intervención de las masas y destinado a que las cosas cambien para que, en definitiva, sigan igual. La independencia hubiera sido una 'revolución social' si a la presencia de una 'burguesía consciente' se añadía un 'estado de ánimo revolucionario en la clase campesina', pero ninguna de estas dos premisas existía en el Perú de 1821, de manera que la independencia triunfó por la acción de los ejércitos de Caracas y Buenos Aires, ayudados por una coyuntura mundial favorable a Inglaterra y perjudicial a España. Es así como, frente a la independencia resultado de un proceso natural, ansiada por todos los peruanos, expresión de la existencia de una nación, existía un pensamiento crítico, renuente a ser arrastrado por la mitificación del pasado (Galindo, 1987, págs. 123-124).

Evitando la mitificación de la independencia y siguiendo a Mariátegui, habló también de nuestra proclividad para experimentar los fracasos de nuestra historia como una frustración:

La frustración, el desánimo, la ausencia de esperanzas son sentimientos frecuentes en los escritores peruanos. Luis Alberto Sánchez, en un libro reciente, define al Perú, paradójicamente, como un país que no ha encontrado aún su clave. Desde otra generación y en una trinchera opuesta, Luis Pásara arriesga la definición de un 'país en derrota' [...] no se trata de una simple postura intelectual, ni de un sentimiento pasajero [...] se podría buscar las filiaciones de este desánimo mediante la lectura de Riva-Agüero, los García Calderón, Gonzáles Prada [...] no han faltado quienes [...] se han preguntado obsesivamente por el origen de esta frustración colectiva, por el momento que según la gráfica expresión de Zavalita, personaje de Vargas Llosa en Conversación en la Catedral, 'se jodió el Perú'. Dejando a un lado la prolija enumeración de proyectos abortados y desengaños colectivos, tres fechas vendrían de inmediato al recuerdo: la conquista, la independencia y la guerra del Pacífico. Por razones que exigirían una indagación mayor en la memoria histórica colectiva, de los tres momentos históricos, los años en que transcurre la independencia, entre 1780 y 1821, han terminado arremolinando el interés casi inevitable de la mayoría de historiadores [...] si experimentamos a la 
independencia como una frustración es porque, como pensaron muchos protagonistas de los levantamientos y batallas, abrió la posibilidad de pensar en un desenlace diferente. La presencia obsesiva del tema en nuestra historiografía se explica si consideramos que persiste, hurtando una frase de Jorge Basadre, como una promesa incumplida (Carlos Contreras y Luis Glave, 2015, págs. 193-208).

No debería haber razón alguna para se siga sintiendo a la independencia como una frustración, y para que quede suelta la ilusión de que también abrió la posibilidad de pensar en un desenlace diferente; frustración que probablemente se deba, como ha señalado el historiador Charles Walker, a que el Perú es un país donde la historia pesa mucho, un país en donde se sufre demasiado del pasado, pasado que sigue siendo abrumador en su repliegue en los mundos culturales de andinos y nativos, y que nos ha llevado a que percibamos el presente y el futuro desde una memoria dañada, a imaginar a la República como si solo tuviera por delante el devenir de una promesa que será siempre incumplida, lo que no sería más que el remanente de una historia que no terminamos de comprender, una curiosidad en la que la historiografía crítica insiste con la intención de dejar suelta la idea de que la fundación de la República nos heredó a una nación inacabada y aún en formación, historiografía que no advierte que la frustración de la que habla viene del lugar de esa memoria dañada; memoria que ha encontrado en la literatura su mejor versión, y de la que ha hablado también Renato Cisneros en su novela "La distancia que nos separa" cuando vuelve a los recuerdos de familia que más dolor le dejaran en la piel y el alma, y que le hacen decir que los recuerdos que persisten no son el síntoma de una memoria saludable, sino el de una memoria dañada, quien sin duda, no desde la novela sino desde la historia, podría haberles dicho a los historiadores de esta historiografía que lo que más recuerdan es lo que más les perturba.

\section{CONCLUSIÓN:}

1. No podemos sentirnos los peruanos satisfechos con los recuerdos que tenemos de nuestra historia moderna y contemporánea, insatisfacción debida al descuido del Ministerio de Educación en la formación de los estudiantes en la historia del Perú, y a un profesorado que influido por ideales de la izquierda socialista y la historiografía crítica enseña una historia que no deja de cuestionar la importancia histórica de la independencia y de la República fundada en 1821, afectando así la forma en que hemos terminado relacionándonos con nuestra historia.

2. La historiografía oficial y la historiografía crítica al haber dado origen a dos proyectos ideológicos y políticos para imaginar la construcción de la república, al proyecto de la nación mestiza, y al proyecto de la nación en formación, no solo han afectado la formación de la peruanidad y su identidad, sino las posibilidades de imaginar de manera diferente el futuro de nuestra República en el mundo del siglo XXI-XXII que está irrumpiendo con el desarrollo de la ciencia y la tecnología.

3. Si digo que somos una República en extinción es no solo porque ésta ha sido secuestrada por la corrupción y la mediocridad, sino porque no hacemos nada que indique que nos estamos preparando para el mundo del futuro, sobre todo desde la investigación científica y tecnológica, las obras de ingeniería y proyectos de desarrollo que necesitamos para no ser un país marginal en el mundo que viene.

\section{REFERENCIAS}

- Amado, D. (2017). El estandarte real y la mascapaycha: Historia de una institución Inca colonial. Lima: Fondo Editorial de la PUCP.

- Basadre, J. (2004). Memoria y destino del Perú: textos esenciales. Lima: Fondo Editorial del Congreso del Perú. 
- $\quad$ Bondy, A. S. (1973). Escila y Caribdis. Lima: Industrial Gráfica S.A.

- Carlos Contreras y Luis Glave. (2015). La independencia del Perú: ¿concedida, conseguida, concebida? Lima: Instituto de Estudios Peruanos.

- Galindo, A. F. (1987). Independencia y revolución 1780-1840. Lima: Instituto Nacional de Cultura.

- Galindo, A. F. (1994). Buscando un Inca. Identidad y utopía en los andes. Lima: Horizonte.

- Heraclio Bonilla y Karen Spalding. (1972). La independencia en el Perú: Las palabras y los hechos. En H. B. al., La independencia en el Perú (págs. 15-64). Lima: Campodónico Ediciones S.A.

- Herren, R. (1997). La conquista erótica de las Indias. Barcelona: Planeta-De Agostini.

- Mariátegui, J. C. (2007). 7 ensayos de interpretación de la realidad peruana. Caracas: Fundación Biblioteca Ayacucho.

- $\quad$ Mc Evoy, C. y Rabinoich, A. (2018). Tiempo de guerra. Lima: Fondo Editorial de la PUCP.

- Pásara, L. (2017). La ilusión de un país distinto cambiar el Perú: de una generación a otra. Lima: Fondo Editorial de la PUCP.

- Portocarrero, G. (2007). Racismo y mestizaje, y otros ensayos. Lima: Fondo Editorial del Congreso del Perú.

- $\quad$ Valcárcel, L. E. (1975). Tempestad en los Andes. Lima: Universo S.A.

- Vergara, A. (2018). Ciudadanos sin república. Lima: Planeta.

- Vich, V. (2003). Borrachos de amor: Las luchas por la ciudadanía en el cancionero popular peruano. Lima: Instituto de Estudios Peruanos .

- Yepes, E. (2004). Jorge Basadre: Memoria y destino del Perú. Textos esenciales. Lima: Fondo Editorial del Congreso del Perú. 